\title{
A comparison of fate and toxicity of selenite, biogenically, and chemically synthesized selenium nanoparticles to zebrafish (Danio rerio) embryogenesis
}

Joyabrata Mal, Wouter J. Veneman, Y. V. Nancharaiah, Eric D. van Hullebusch, Willie J. G. M. Peijnenburg, Martina G. Vijver \& Piet N. L. Lens

To cite this article: Joyabrata Mal, Wouter J. Veneman, Y. V. Nancharaiah, Eric D. van Hullebusch, Willie J. G. M. Peijnenburg, Martina G. Vijver \& Piet N. L. Lens (2017) A comparison of fate and toxicity of selenite, biogenically, and chemically synthesized selenium nanoparticles to zebrafish (Danio rerio) embryogenesis, Nanotoxicology, 11:1, 87-97, DOI: 10.1080/17435390.2016.1275866

To link to this article: http://dx.doi.org/10.1080/17435390.2016.1275866

+ View supplementary material $₫$

Submit your article to this journal $[\pi$
Accepted author version posted online: 23 Dec 2016 Published online: 09 Jan 2017.

III Article views: 77 


\title{
A comparison of fate and toxicity of selenite, biogenically, and chemically synthesized selenium nanoparticles to zebrafish (Danio rerio) embryogenesis
}

\author{
Joyabrata Mal ${ }^{\mathrm{a}, \mathrm{b}, \mathrm{c}}$, Wouter J. Veneman ${ }^{\mathrm{b}}$, Y. V. Nancharaiah ${ }^{\mathrm{d}, \mathrm{e}}$, Eric D. van Hullebusch ${ }^{\mathrm{a}, \mathrm{b}}$, \\ Willie J. G. M. Peijnenburg ${ }^{b, f}$, Martina G. Vijver ${ }^{b}$ and Piet N. L. Lens ${ }^{a, g}$
}

\begin{abstract}
${ }^{\mathrm{a} U N E S C O-I H E}$, Delft, The Netherlands; ${ }^{\mathrm{b}}$ Institute of Environmental Sciences (CML), Faculty of Science, Leiden University, Leiden, The Netherlands; 'Université Paris-Est, Laboratoire Géomatériaux et Environnement (EA 4508), UPEM, Marne-la-Vallée, France; ${ }^{\mathrm{d} B i o f o u l i n g}$ and Biofilm Process Section, Water and Steam Chemistry Division, Bhabha Atomic Research Centre, Kalpakkam, Tamil Nadu, India; ${ }^{\mathrm{e}} \mathrm{Homi}$ Bhabha National Institute, Anushakti Nagar, Mumbai, India; ${ }^{f}$ RIVM-National Institute of Public Health and the Environment, Center for Safety of Substances and Products, Bilthoven, The Netherlands; ${ }^{9}$ Department of Chemistry and Bioengineering, Tampere University of Technology, Tampere, Finland
\end{abstract}

\begin{abstract}
Microbial reduction of selenium (Se) oxyanions to elemental Se is a promising technology for bioremediation and treatment of Se wastewaters. But a fraction of biogenic nano-Selenium (nano-Se ${ }^{b}$ ) formed in bioreactors remains suspended in the treated waters, thus entering the aquatic environment. The present study investigated the toxicity of nano-Se $\mathrm{e}^{\mathrm{b}}$ formed by anaerobic granular sludge biofilms on zebrafish embryos in comparison with selenite and chemogenic nano-Se (nano-Se $e^{c}$. The nano-Se ${ }^{b}$ formed by granular sludge biofilms showed a $L_{50}$ value of $1.77 \mathrm{mg} / \mathrm{L}$, which was 3.2 -fold less toxic to zebrafish embryos than selenite $\left(\mathrm{LC}_{50}=0.55 \mathrm{mg} / \mathrm{L}\right)$ and 10 -fold less toxic than bovine serum albumin stabilized nano-Se ${ }^{c}\left(\mathrm{LC}_{50}=0.16 \mathrm{mg} / \mathrm{L}\right)$. Smaller (nano-Se $e^{\mathrm{cs}}$; particle diameter range: $25-80 \mathrm{~nm}$ ) and larger (nano-Se ${ }^{\mathrm{cl}}$; particle diameter range: $50-250 \mathrm{~nm}$ ) sized chemically synthesized nano-Se ${ }^{c}$ particles showed comparable toxicity on zebrafish embryos. The lower toxicity of nano-Se $\mathrm{e}^{\mathrm{b}}$ in comparison with nano-Se $\mathrm{e}^{c}$ was analyzed in terms of the stabilizing organic layer. The results confirmed that the organic layer extracted from the nano-Se ${ }^{b}$ consisted of components of the extracellular polymeric substances (EPS) matrix, which govern the physiochemical stability and surface properties like $\zeta$-potential of nano-Se ${ }^{b}$. Based on the data, it is contented that the presence of humic acid like substances of EPS on the surface of nano-Se ${ }^{b}$ plays a major role in lowering the bioavailability (uptake) and toxicity of nano-Se $\mathrm{e}^{\mathrm{b}}$ by decreasing the interactions between nanoparticles and embryos.
\end{abstract}

\section{ARTICLE HISTORY}

Received 8 February 2016 Revised 14 November 2016 Accepted 13 December 2016

\section{KEYWORDS}

Biogenic nanomaterials; selenium bioremediation; zebrafish; EPS;

nanotoxicology

\section{Introduction}

Selenium (Se) is an essential micronutrient in organisms including humans. It plays a very important role in several cellular processes including thyroid hormone production and in mitigating oxidative stress (Rayman, 2006). However, at concentrations of one order excess of its essential level, Se becomes a potential toxic element (Lenz \& Lens, 2009; Winkel et al., 2012). Se contamination of aquatic bodies generally occurs through discharge of different waste streams such as acid mine drainage, coal and phosphate mining effluents, flue gas desulphurization waters and agriculture drainage (Mal et al., 2016; Nancharaiah \& Lens, 2015a). Elemental $\mathrm{Se}(\mathrm{Se}(0))$ is an integral component of the natural Se cycle often formed in oxygen limited environments, with microorganisms playing a key role in bioreduction of Se oxyanions (selenite and selenate) (Winkel et al., 2012). In fact, conversion of soluble $\mathrm{Se}$ oxyanions to insoluble $\mathrm{Se}(0)$ is a key process for in situ bioremediation and treatment of Se-contaminated waters and wastewaters (Nancharaiah \& Lens, 2015a,b). But a significant fraction of $\mathrm{Se}(0)$ formed by microbial reduction remains in the bioreactor effluent, leading to the discharge of $\mathrm{Se}(0)$ in the environment. Abiotic reduction of selenite under reducing environments, by e.g. Fe(II)-containing mineral surfaces may also lead to significant deposition of $\mathrm{Se}(0)$ in natural environments as sediments, groundwater, or nuclear waste disposal geological media (Scheinost et al., 2008).

Se pollution of aquatic environments is a concern mainly because this element can cross trophic levels of the food-chain and gets biomagnified, showing an unusual high bioaccumulation potential and exhibiting teratogenic effects on aquatic organisms (Dennis, 2004). Moreover, the toxicity of Se on aquatic organisms depends on its chemical (inorganic and organic) and physical (liquid, solid, and gas) status and concentration. Biogenic elemental Se (nano-Se ${ }^{b}$ ) is always in the form of nanoparticles (nano-Se) with a maximum size up to $\sim 400 \mathrm{~nm}$, thus bringing nanotoxicology aspects (e.g. dissolution, entry into cells, surface chemistry, and reactivity) into consideration (Buchs et al., 2013; Winkel et al., 2012). Although the average particle size of nano-Se ${ }^{b}$ is more than $100 \mathrm{~nm}$, microbially produced $\mathrm{Se}(0)$ is often referred to as nano-Se in the literature (Jain et al., 2015; Srivastava \& Mukhopadhyay, 2013; Zhang et al., 2011). In addition, the particles of nano-Se ${ }^{b}$ formed by microorganisms are colloidal in nature (Buchs et al., 2013); hence the term nano-selenium is used in this paper. 
Compared with soluble oxyanions, $\mathrm{Se}(0)$ is considered to be less bioavailable and reactive. However, some researchers have reported that the uptake of $\mathrm{Se}(0)$ by marine bivalve mollusks, such as Macoma balthica or Potamocorbula amurensis (Luoma et al., 2000; Schlekat et al., 2000). Macoma balthica ingests sediments with $>1.5 \mu \mathrm{g}$ selenium $/ \mathrm{g}$, a concentration that could achieve steady-state tissue burdens approaching the level toxic to fish. Thus, it is necessary that treatment of selenium containing waters by stimulation of microbial dissimilatory reduction of selenium oxyanions should be considered in efforts to avoid discharge and to reduce hazardous exposure to selenium at highly contaminated sites. However, studies on the fate and toxicity of nano-Se, particularly on nano- $\mathrm{Se}^{\mathrm{b}}$ in environmentally relevant conditions, are limited and the available information is contradictory. Chemically synthesized nano-Se (nano-Sec) was reported to be seven-fold less toxic than selenite when exposed orally to mice and rats (Zhang et al., 2001). But, the bioavailability (uptake) of nano-Se ${ }^{c}$ was comparable with that of selenite. A subsequent study showed a five-fold higher toxicity for nano-Se $\mathrm{S}^{\mathrm{c}}$ than selenite on juvenile medaka fish due to hyper-accumulation and slowed clearance of nano-Se ${ }^{c}$ from the liver (Li et al., 2008).

The colloidal stability of nano-Se $\mathrm{e}^{\mathrm{b}}$ is governed by the associated organic layer, which originates from the microorganisms and their extracellular polymeric substances (EPS) (Buchs et al., 2013; Jain et al., 2015). In natural and engineered settings, the EPS matrix of biofilms plays a critical role in determining the transport, fate, and toxicity of engineered nanoparticles (NPs). It has been suggested that the natural organic matter (NOM) available in surface and ground waters influences the bioavailability of selenium oxyanion (e.g. selenite) (Zhang \& Moore, 1996). Several studies have shown that organic matter, i.e. EPS and humic substances, influence the fate (size, shape or surface charge) and toxicity of engineered nanoparticles like $\mathrm{Ag}, \mathrm{TiO}_{2}, \mathrm{ZnS}$ by limiting their dissolution and bioavailability (uptake) (Bondarenko et al., 2016; Gao et al., 2012; Lin et al., 2012; Moreau et al., 2007). But it is unclear whether NOM or EPS of biofilms associate with elemental selenium and influence the nano-Se bioavailability and toxicity.

In the present study, experimental work was designed to investigate the toxicity of nano-Se ${ }^{b}$ formed in bioreactors treating selenium wastewater. Zebrafish embryos were chosen because zebrafish is an ideal vertebrate model organism for studying the effects of environmental contaminants on developmental processes. In addition, the transparency of the zebrafish embryos allows continuous observation of developmental changes during organogenesis (Lohr \& Yost, 2000). The toxicity of nano-Se ${ }^{b}$ was compared with those of nano-Se $\mathrm{e}^{\mathrm{c}}$ and selenite. Two different sizes of nano-Se ${ }^{c}$ were taken into consideration to determine the effect of particle size on toxicity. The fate of nano-Se was determined in terms of shape, size, aggregation, and dissolution kinetics. The organic constituents of the surface coating associated with nano$\mathrm{Se}^{\mathrm{b}}$ was characterized to better understand the importance of the surface coating and compare its influence on the fate and toxicity of nano-Se to the zebrafish embryos with bovine serum albumin (BSA)-capped nano-Sec.

\section{Materials and methods}

\section{Chemicals}

Sodium selenite $\left(\mathrm{Na}_{2} \mathrm{SeO}_{3}\right)$ was purchased from Sigma-Aldrich (St. Louis, MO) and was used as received. All other chemicals used were of analytical grade and purchased from Merck (Darmstadt, Germany). Nano-Se ${ }^{b}$ and nano-Se ${ }^{c}$ were prepared by biological and chemical reduction, respectively, as described below.

\section{Nano-Se production}

Nano-Se ${ }^{b}$ was produced through bioreduction of selenite by anaerobic granular sludge. Anaerobic granular sludge collected from a full-scale upflow anaerobic sludge blanket (UASB) reactor treating paper mill wastewater (Industriewater Eerbeek B.V., Eerbeek, The Netherlands) was utilized as the source of microorganisms for selenite reduction. The mineral medium used for biogenic selenium synthesis contained (mg/L) $\mathrm{NH}_{4} \mathrm{Cl}$ (300), $\mathrm{CaCl}_{2} .2 \mathrm{H}_{2} \mathrm{O}$ (15), $\mathrm{KH}_{2} \mathrm{PO}_{4}$ (250), $\mathrm{Na}_{2} \mathrm{HPO}_{4}$ (250), $\mathrm{MgCl}_{2}$ (120), and $\mathrm{KCl}$ (250). Sodium lactate $(5 \mathrm{mM})$ and $\mathrm{Na}_{2} \mathrm{SeO}_{3}(1 \mathrm{mM})$ were used as the electron donor and the electron acceptor, respectively. The $\mathrm{pH}$ of the mineral medium was adjusted to 7.3. The serum bottles with $400 \mathrm{~mL}$ mineral medium and granular sludge $(4.0 \mathrm{~g}$ wet weight) were closed with butyl rubber septa, then purged with $\mathrm{N}_{2}$ gas for $\sim 5 \mathrm{~min}$, and incubated at $30^{\circ} \mathrm{C}$ for $7 \mathrm{~d}$ in an orbital shaker set at $150 \mathrm{rpm}$. Formation of nano- $\mathrm{Se}^{\mathrm{b}}$ was confirmed by the appearance of a red color and disappearance of selenite. After the incubation period, the supernatant was decanted from the serum bottles and the suspended biomass was removed by centrifugation (Hermle Z36K, Hermle Labortechnik, Wehingen, Germany) at $3000 \mathrm{~g}, 4^{\circ} \mathrm{C}$ for $15 \mathrm{~min}$. The supernatant was centrifuged again at $37,000 \mathrm{~g}, 4^{\circ} \mathrm{C}$ for $15 \mathrm{~min}$. The red colored pellet was suspended in Milli-Q (18 $\mathrm{M} \Omega \mathrm{cm}$ ) water by sonication and purified by hexane (Jain et al., 2015).

Nano-Se $e^{c}$ was produced through chemical reduction of selenite as described by Zhou et al. (2014). Briefly, selenite $(0.1 \mathrm{M}, 500 \mu \mathrm{L})$ was mixed with a $2.5 \mathrm{~mL}$ solution containing $15.5 \mathrm{mg}$ of glutathione and $10 \mathrm{mg}$ of BSA for production of smaller sized nano-Se (nano-Se ${ }^{c s}$ ) particles. Larger sized nano-Se (nano-Se ${ }^{c l}$ ) particles were prepared by using $15.5 \mathrm{mg}$ of glutathione and $4 \mathrm{mg}$ of BSA. Within $5 \mathrm{~min}$, the color of the solution turned from colorless to red due to the formation of the nano-Sec .

The nano-Se ${ }^{b}$ and nano-Se ${ }^{c}$ (nano-Se ${ }^{c s}$ and nano-Se ${ }^{c s}$ ) particles were rinsed several times in Milli-Q $(18 \mathrm{M} \Omega \mathrm{cm})$ water and collected by centrifugation at $37,000 \mathrm{~g}, 4^{\circ} \mathrm{C}$ for $30 \mathrm{~min}$. The pellets were dried at $30^{\circ} \mathrm{C}$ to obtain nano-Se in a powdered form. Heating was avoided as amorphous $\mathrm{Se}(0)$ undergoes a glass transition at temperatures above $30-35^{\circ} \mathrm{C}$ (Pearce et al., 2009).

\section{Stock solutions of selenite, nano-Se $e^{b}$ and nano-Se $e^{c}$}

The selenite stock was prepared by dissolving $1 \mathrm{~g} / \mathrm{L}$ of sodium selenite $\left(\mathrm{Na}_{2} \mathrm{SeO}_{3}, 99 \%\right.$ purity) in ultrapure water. Nano-Se ${ }^{\mathrm{b}}$, nano$\mathrm{Se}^{\mathrm{cs}}$, and nano-Se ${ }^{\mathrm{cl}}$ stocks were prepared by suspending, respective, $100 \mathrm{mg} / \mathrm{L}$ powder in ultrapure water. The suspensions were sonicated for $15 \mathrm{~min}$ using $\mathrm{S} 40 \mathrm{~h}$ Elmasonic water bath sonicator. The Se concentration was determined in the stock solutions by inductively coupled plasma-mass spectrometry (ICP-MS) after acidification in $0.6 \mathrm{M} \mathrm{HNO}_{3}$.

\section{Characterization of nano-Se}

The size and morphology of the nano- $\mathrm{Se}^{\mathrm{b}}$, nano-Se $\mathrm{e}^{\mathrm{cs}}$, and nano$\mathrm{Se}^{\mathrm{cl}}$ suspension in egg water $\left(0.21 \mathrm{~g}\right.$ Instant Ocean ${ }^{\circledR}$ salt in $1 \mathrm{~L}$ Milli-Q water, $\mathrm{pH}$ 6.5-7.0) after 1 and $24 \mathrm{~h}$ of incubation were characterized using transmission electron microscope (TEM) (JEOL 1010, JEOL Inc., Tokyo, Japan). For sample preparation, a drop of egg water containing nano-Se was deposited onto a 400 mesh $\mathrm{Cu}$ grid coated with a carbon support film. After drying at room temperature, TEM analysis was performed. Dynamic light scattering of samples was performed on a Zetasizer Nano-ZS instrument (Malvern Instruments, Malvern, UK) for determining the size distribution and zeta $(\zeta)$-potential of nano-Se particles suspended in 
egg water. Nano-Se suspensions having 1 and $5 \mathrm{mg} / \mathrm{L}$ Se were prepared in egg water. Samples were drawn at $1 \mathrm{~h}$ and $24 \mathrm{~h}$ of preparation for measurements. A maximum incubation of $24 \mathrm{~h}$ was chosen because the medium of the zebrafish embryos assay was changed every $24 \mathrm{~h}$. Nano-Se ${ }^{b}$ was also characterized by a scanning electron microscope (SEM) equipped with an energy dispersive X-ray spectra system (EDXS) (see Supporting information for more details).

\section{Characterization of organic material associated with nano-Se}

Organic material was extracted from nano-Se ${ }^{b}$ and nano- $\mathrm{Se}^{c}$ using the formaldehyde $\left(0.06 \mathrm{~mL}\right.$ of $36.5 \%$ formaldehyde, at $4{ }^{\circ} \mathrm{C}$ for $\left.1 \mathrm{~h}\right)$ plus $\mathrm{NaOH}\left(1 \mathrm{~N}\right.$; at $4{ }^{\circ} \mathrm{C}$ for $3 \mathrm{~h}$ ) extraction method (Liu \& Fang, 2002). The extracted sample was centrifuged at $20,000 \mathrm{~g}$ for $20 \mathrm{~min}$, then filtered with a $0.22 \mu \mathrm{m}$ acetate filter and finally diluted in water to bring the dissolved total organic carbon (TOC) concentration to $\sim 10 \mathrm{mg} / \mathrm{L}$. A Phenix 8000 TOC-meter (Dohrmann, Waite Park, MN) was used to measure the TOC. Organic material in the diluted extract was characterized by its three-dimensional excitation-emission matrix (3D-EEM) recorded using a FluoroMax-3 spectrofluorometer (HORIBA Jobin Yvon, Edison, NJ) (Bhatia et al., 2013; Maeng et al., 2012). The EEM spectra were obtained at excitation wavelengths between 240 and $450 \mathrm{~nm}$ at $10 \mathrm{~nm}$ intervals, and emission wavelengths between 290 and $500 \mathrm{~nm}$. The 3D spectra were divided and expressed into five regions, each region associated with different compounds: derived from proteins tyrosine (I) and tryptophan (II) corresponding to aromatic proteins, fulvic-like acids (III), soluble microbial by-products (SMP) (IV), and humic-like substances (V) (Baker \& Lamont-Black, 2001; Leenheer \& Croue, 2003; Maeng et al., 2012).

\section{Dissolution kinetics of nano-Se}

The dissolution of nano-Se, if any, was determined in exposure medium (i.e. egg water) used for toxicity tests. Suspension of nano-Se $e^{b}$ and nano-Se ${ }^{c}$ (nano-Se $e^{c s}$ and nano-Se $e^{c l}$, both) at $1 \mathrm{mg} / \mathrm{L}$ Se was prepared in exposure medium and incubated for a maximum period of $24 \mathrm{~h}$. At different time intervals $(0,8$, and $24 \mathrm{~h}$ ), the dissolved Se concentration was determined. The suspension containing nano-Se $e^{b}$ and nano-Se ${ }^{c}$ were first centrifuged at $40,000 \mathrm{~g}$ for $30 \mathrm{~min}$ at $4{ }^{\circ} \mathrm{C}$ (Hermle Z36K, Hermle Labortechnik, Wehingen, Germany). Supernatants were filtered through $0.05 \mu \mathrm{m}$ syringe filter (Antop 25, Whatman, GE Life Sciences, San Francisco, CA). Se concentrations were measured in the filtrates using atomic absorption spectrophotometer (AAS) (SOLAAR MQZE, Unity Lab Services, Waltham, MA) after acidification in $0.6 \mathrm{M} \mathrm{HNO}_{3}$. The presence of selenite and selenate in supernatants was monitored at $24 \mathrm{~h}$ to confirm any reoxidation of nano-Se ${ }^{b}$ or nano- $\mathrm{Se}^{\mathrm{c}}$ to selenite or selenate. Selenate was determined by ion chromatography (IC), equipped with an AS4A column with the retention time of selenate at $10.3 \mathrm{~min}$. For selenite analysis, a spectrophotometric method was followed as described in Mal et al. (2016). Briefly, the supernatant $(1 \mathrm{~mL})$ was mixed with $0.5 \mathrm{~mL}$ of $4 \mathrm{M} \mathrm{HCl}$, and then with $1 \mathrm{~mL}$ of $1 \mathrm{M}$ ascorbic acid. After $10 \mathrm{~min}$ of incubation at room temperature, the absorbance was determined at $500 \mathrm{~nm}$ using an UV-Vis spectrophotometer (Hermle Z36 HK Hermle Labortechnik, Wehingen, Germany).

\section{Toxicity assay of selenite, nano-Se $e^{b}$ and nano-Se $e^{c}$ on zebrafish embryos}

ABxTL wild-type adult zebrafish was maintained at $25( \pm 5)^{\circ} \mathrm{C}$ in a $14 \mathrm{~h}$ light: $10 \mathrm{~h}$ dark cycle. Fertilized zebrafish eggs obtained from adults were distributed into 96-well plates at 1 egg each per well. An acute exposure regime of $96 \mathrm{~h}$ was used, from 24 to $120 \mathrm{~h}$ post-fertilization (hpf), thus including the major stages of organ development. At $24 \mathrm{hpf}$, the embryos were exposed to $250 \mu \mathrm{L} /$ well of freshly prepared egg water containing $\mathrm{Na}_{2} \mathrm{SeO}_{3}$, nano-Se ${ }^{\mathrm{b}}$, nano-Se $e^{c s}$, and nano-Se ${ }^{c l}$. Nominal concentrations of $0.2,0.4,0.6$, 0.8 , and $1.0 \mathrm{mg} / \mathrm{L}$ of $\mathrm{Na}_{2} \mathrm{SeO}_{3}$ and $0.05,0.1,0.2,0.5,1,2$, and $5 \mathrm{mg} / \mathrm{L}$ of nano-Se ${ }^{\mathrm{b}}$, nano-Se ${ }^{\mathrm{cl}}$, or nano-Se ${ }^{\mathrm{cs}}$ were prepared in egg water. The suspensions were sonicated for $15 \mathrm{~min}$ in an $\mathrm{S} 40 \mathrm{~h}$ Elmasonic water bath sonicator and then exposed to embryos immediately. Multi-well plates containing embryos in egg water were kept at $28^{\circ} \mathrm{C}$. The exposure medium $(200 \mu \mathrm{L})$ was always replaced with a freshly prepared medium containing either selenite or nano-Se every day up to $120 \mathrm{hpf}$ according to Organization for Economic Co-operation and Development (OECD) guideline 157 (OECD, 2011).

Duplicate trials containing 8 embryos per treatment group were used. Mortality and hatching rates were determined at 48, 72, 96, and $120 \mathrm{hpf}$ using a dissecting stereomicroscope (Leica M165C, Wetzlar, Germany). Embryos were scored as dead based on criteria according to OECD guideline 157. For the median lethal concentration $\left(\mathrm{LC}_{50}\right)$ calculation, mortality data obtained at 120 hpf was used. The $\mathrm{LC}_{50}$ was determined based on plotting mortality data on a cumulative curve obtained from two independent experiments at $120 \mathrm{hpf}$. The LC $_{50}$ values of zebrafish embryos for selenite and nano-Se were calculated using a non-linear dose response function available in GraphPad Prism 5 (GraphPad Inc., San Deigo, CA):

$$
E=\frac{\text { Bottom }+(\text { Top }- \text { Bottom })}{1+\frac{10\left(\log L C_{50}-\log C\right)}{\rho}}
$$

where $E$ is the mortality effect on zebrafish embryos (scaled 0-1) and top and bottom are plateaus in the units of the $y$ axis, with the top and the bottom of mortality being $100 \%$ and $0 \%$, respectively. The term $C$ is the initial actual exposure concentration of selenite or nano-Se, and $\rho$ is the slope of the curve.

The toxicity of nano-Se ${ }^{b}$ and nano- $\mathrm{Se}^{c}$ to zebrafish embryos was determined as total nano-Se ${ }^{b}{ }_{\text {total }}$ and nano- $\mathrm{Se}^{\mathrm{c}}{ }_{\text {total }}$ which is the sum of the contributions of both nano-Se $\mathrm{e}_{\text {particle }}$ and nano$\mathrm{Se}_{\text {ion. }}$. The actual concentrations of nano-Se $e_{\text {ion }}$ and nano-Setot were measured by AAS at the end of $24 \mathrm{~h}$ incubation in the exposure medium as described previously. The toxicity of nano$\mathrm{Se}_{\text {ion }}$ can be measured by the concentration-response curve of $\mathrm{Na}_{2} \mathrm{SeO}_{3}$. Therefore, mortality of embryos induced solely by nano$\mathrm{Se}_{\text {particle }}$ was calculated by using the response addition model (Backhaus et al., 2000):

$$
E_{\text {total }}=1-\left[\left(1-E_{\text {ion }}\right)\left(1-E_{\text {particles }}\right)\right]
$$

where $E_{\text {total }}, E_{\text {ion, }}$ and $E_{\text {particle }}$ represent the effect on zebrafish embryos caused by the nano-Se $e_{\text {total }}$ nano-Se $e_{\text {ion, }}$ and nano-Se $e_{\text {particle }}$ (scaled 0-1), respectively, which makes $E_{\text {particle }}$ as the only unknown, allowing for direct calculation of the effect caused by the particles at any specific initial actual particle concentration.

\section{Statistical analysis}

All the data were expressed as mean with a 95\% confidence interval (C.I.) or standard error of the mean. In order to compare the differences between treatments and controls, statistical analysis using one-way analysis of variance (ANOVA) with Tukey's multiple 

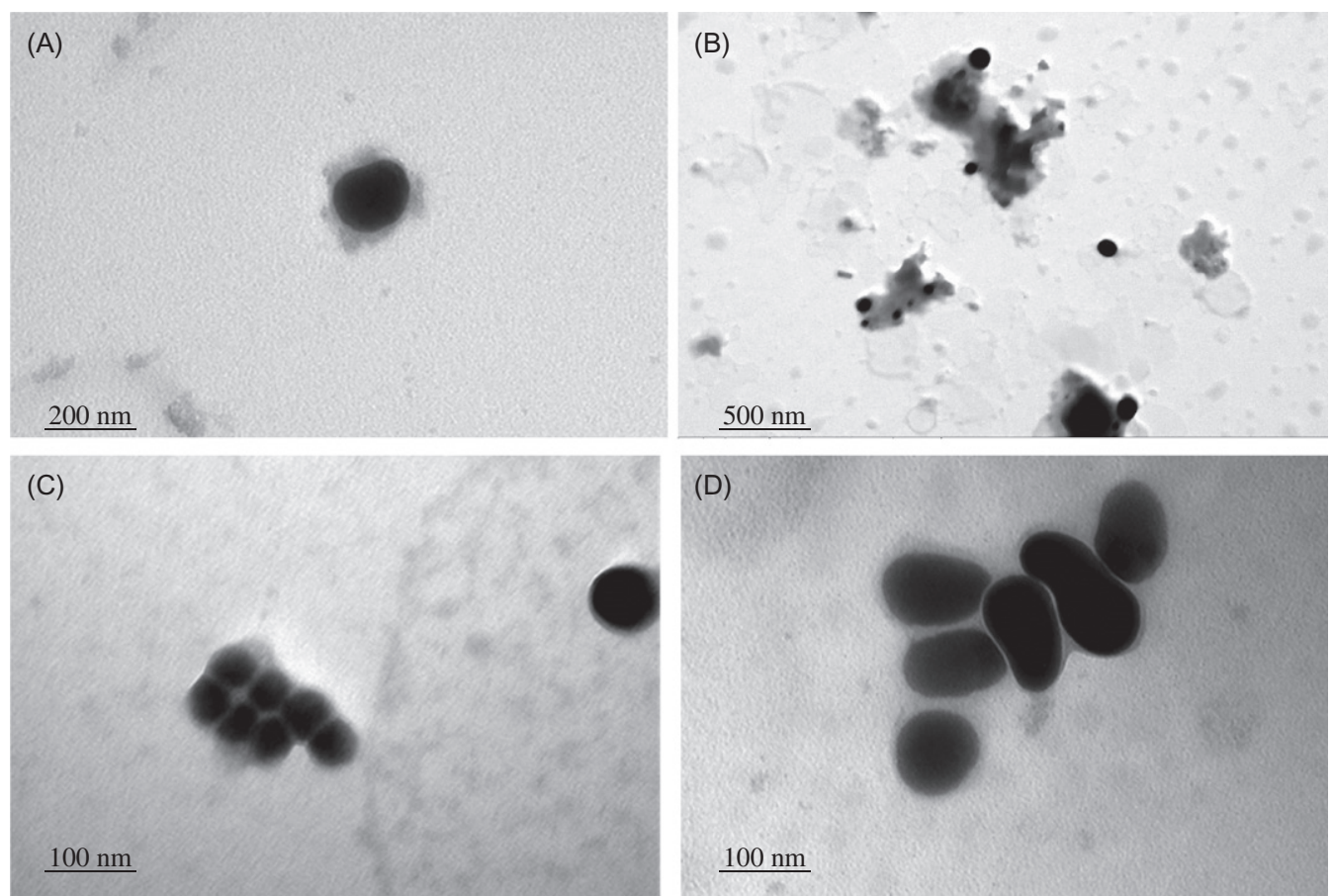

Figure 1. Transmission electron microscopic images of nano-Se particles in egg water: $(A, B)$ nano-Se ${ }^{b},(C)$ nano-Se ${ }^{c s}$, and $(D)$ nano-Se ${ }^{c l}$.

Table 1. Particle size distribution, zeta-potential of nano-Se ${ }^{\mathrm{b}}$, nano-Se $\mathrm{S}^{\mathrm{cs}}$ and nano-Se ${ }^{\mathrm{cl}}$ after $1 \mathrm{~h}$ and $24 \mathrm{~h}$ of incubation in egg water.

\begin{tabular}{lcccccc}
\hline & \multicolumn{2}{c}{$\begin{array}{c}\text { Particles size } \\
\text { distribution }(\mathrm{nm})\end{array}$} & & \multicolumn{2}{c}{ Zeta-potential $(\mathrm{mV})$} \\
\cline { 2 - 3 } \cline { 6 - 6 } Nano-Se & $1 \mathrm{~h}$ & $24 \mathrm{~h}$ & & $1 \mathrm{~h}$ & $24 \mathrm{~h}$ \\
\hline Nano-Se $^{\mathrm{b}}$ & $100-400$ & $100-400$ & & $-28.5 \pm 5.19$ & $-28.1 \pm 4.86$ \\
Nano-Se $^{\mathrm{cs}}$ & $25-90$ & $25-100$ & & $-16.2 \pm 3.16$ & $-15.9 \pm 3.97$ \\
Nano-Se $^{\mathrm{cl}}$ & $50-250$ & $50-250$ & & $-13.73 \pm 3.57$ & $-12.78 \pm 4.11$ \\
\hline
\end{tabular}

comparison posttests was performed when required. The significance level in all the calculations was set at $p<0.05$.

\section{Results}

\section{Characterization of nano-Se}

Nano-Se ${ }^{b}$ produced during the bioreduction of selenite by anaerobic granular sludge was spherical in shape as shown by TEM (Figure 1) and SEM (Figure S1) images. EDXS analysis confirmed the presence of selenium as the main element in nano$\mathrm{Se}^{\mathrm{b}}$ samples (Figure S1). In addition, the presence of peaks for carbon, nitrogen, and oxygen were attributed to the organic material associated with the nano-Se $\mathrm{e}^{\mathrm{b}}$. The morphology of the nano-Se $e^{c}$ was also spherical as revealed using TEM imaging (Figure 1).

The particle size distribution and the zeta-potential of all three kinds of nano-Se suspensions in egg water determined after $1 \mathrm{~h}$ and $24 \mathrm{~h}$ of preparation are given in Table 1 . Nano-Se ${ }^{\mathrm{b}}$ particles had sizes ranging from 100 to $350 \mathrm{~nm}$ with an average size of $185 \mathrm{~nm}$ (Figure S2). The size of nano-Se ${ }^{\mathrm{cs}}$ particles, formed in the presence of $10 \mathrm{mg} / \mathrm{L}$ of $\mathrm{BSA}$, ranged from 25 to $90 \mathrm{~nm}$ with an average diameter of $50 \mathrm{~nm}$, while nano- $\mathrm{Se}^{\mathrm{cl}}$ formed at lower BSA concentrations ( $4 \mathrm{mg} / \mathrm{L}$ ) was larger in size and ranged from 50 to 250 with an average diameter of $106 \mathrm{~nm}$ (Figure S2). It was apparent from the data that no significant change in particle size distribution was seen when the particles were suspended in egg water even after $24 \mathrm{~h}$ (Figure S1).
The zeta potential of the nano-Se ${ }^{b}(-28.5 \pm 5.19 \mathrm{mV})$ suspensions was higher than that of both nano-Se ${ }^{c s}(-16.2 \pm 3.16 \mathrm{mV})$ and nano-Se ${ }^{\mathrm{cl}}(-13.73 \pm 3.57 \mathrm{mV})$. There was no marked change in the zeta potential of nano-Se suspended in egg water during $24 \mathrm{~h}$ incubation (Table 1).

\section{Dissolution kinetics of nano-Se}

Release of Se ions, if any, from nano-Se in egg water was determined immediately, and after 8 and $24 \mathrm{~h}$ of incubation (Figure S3). Dissolution of nano-Se $\mathrm{Cs}^{\mathrm{cs}}(5.6 \pm 0.8 \%)$ at $0 \mathrm{~h}$ was relatively higher than nano-Se $\mathrm{Cl}^{\mathrm{cl}}(4.4 \pm 0.17 \%)$ and nano-Se $(1.3 \pm 0.1 \%)$. But, dissolution at $24 \mathrm{~h}$ of nano-Se ${ }^{\mathrm{cl}}$ was comparatively higher than both nano-Se $\mathrm{Cs}^{\mathrm{cs}}$ and nano-Se $\mathrm{e}^{\mathrm{b}}$. The dissolved Se concentration after $24 \mathrm{~h}$ was $3.07( \pm 0.12), 7.76( \pm 0.26)$, and $8.4( \pm 0.4) \%$ of the initial Se $(1 \mathrm{mg} / \mathrm{L})$, respectively, for nano-Se ${ }^{\mathrm{b}}$, nano-Se $\mathrm{e}^{\mathrm{cs}}$, and nano-Se $\mathrm{Cl}^{\mathrm{cl}}$. No trace amounts of selenate (detection limit $50 \mu \mathrm{g} / \mathrm{L}$ ) were found in all three solutions after $24 \mathrm{~h}$ of incubation. No selenite concentrations (detection limit $200 \mu \mathrm{g} / \mathrm{L}$ ) were determined due to marginal nano-Se dissolution.

\section{Fluorescence properties of organic material associated with nano-Se}

The 3D EEM fluorescence spectra corresponding to different components of organic material extracted from nano- $\mathrm{Se}^{c}$ (nano-Se ${ }^{c s}$ and nano-Se $\mathrm{Cl}^{\mathrm{c}}$, both have only BSA as capping agent) and nano$\mathrm{Se}^{\mathrm{b}}$ are shown in Figure 2. The organic material from nano-Se showed fluorescence in the area zones associated with the proteins-tyrosine and tryptophan (I or II) and SMPs (IV) (Figure 2(A)). In addition, peaks corresponding to fulvic-like acids (III) and humic-like (V) substances were evident. However, the relative fluorescence intensity of fulvic and humic-like substances (III and V) was low as compared with the fluorescence intensity of aromatic protein-like (areas I and II) and SMPs (IV). The 3D fluorescence spectra of organic material extracted from BSA stabilized nano-Se ${ }^{c}$ (Figure $\left.2(B)\right)$ exhibited a distinct peak $\left(\lambda_{\mathrm{ex}} \sim 280 \mathrm{~nm}\right.$, 

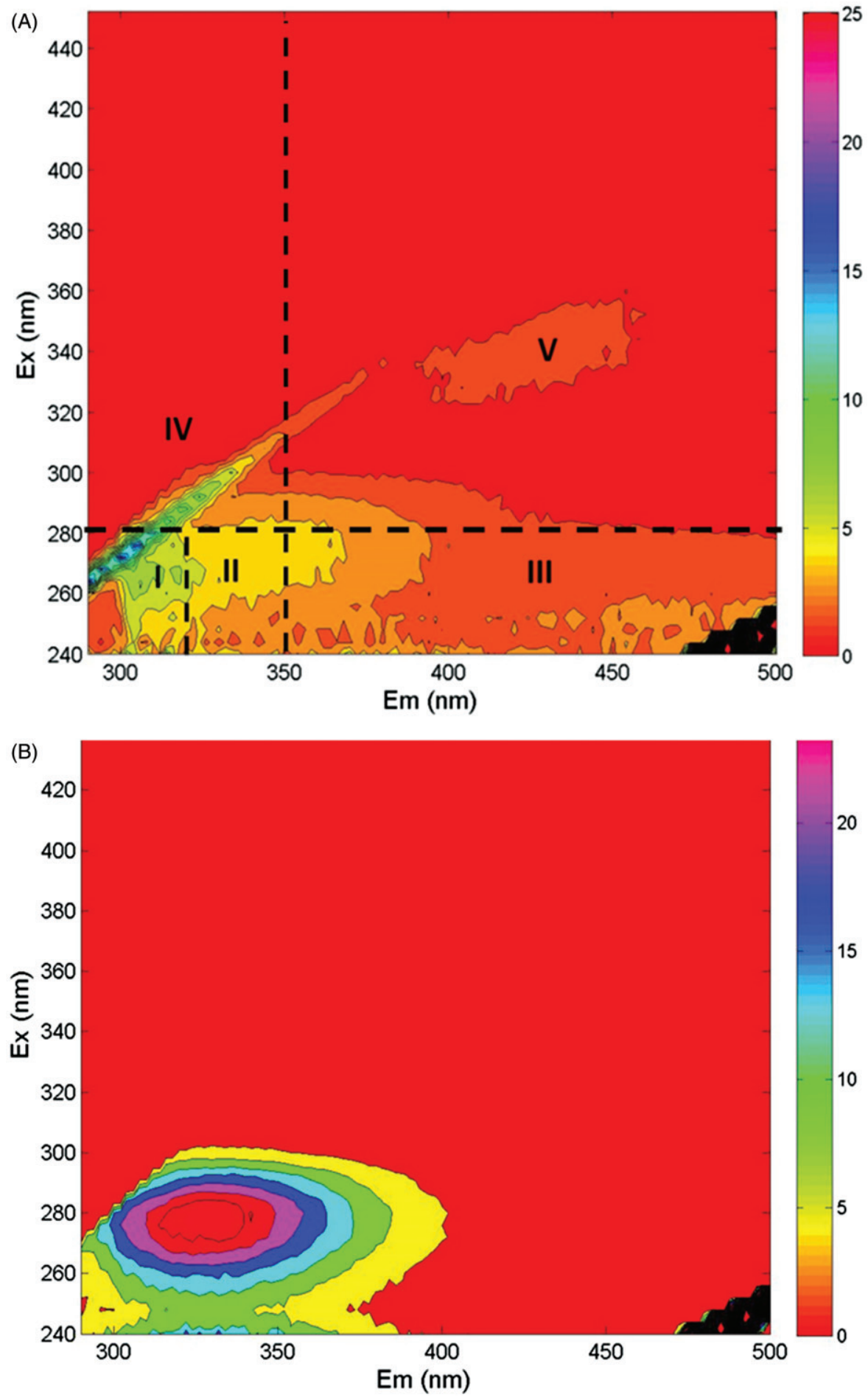

Figure 2. Three-dimensional excitation emission matrix (EEM) fluorescence spectra of extracted organic material. (A) Natural organic material from nano-Se $\mathrm{e}^{\mathrm{b}}$ and (B) BSA from nano-Ses. Region I and II: aromatic proteins; IV: soluble microbial by-products-like; III and V: fulvic acid and humic-like substances.

$\left.\lambda_{\mathrm{em}} \sim 320-350 \mathrm{~nm}\right)$, which can be attributed to both the tryptophan and tyrosine residues of BSA (Ray et al., 2012).

\section{Survival and hatching rate over time}

The time courses of hatching of zebrafish embryos exposed to selenite and nano-Se are shown in Figure 3. In the control, 93.75\% of the embryos were hatched at $72 \mathrm{hpf}$. Compared with the controls, the hatching rates associated with selenite and nano-Se ${ }^{b}$ did not show any significant difference at nominal concentrations of $<1 \mathrm{mg} / \mathrm{L}$ Se and all the embryos hatched. But, at concentrations above $2 \mathrm{mg} / \mathrm{L} \mathrm{Se}$, hatching was delayed as compared with the controls and $75 \%$ and $81 \%$ embryos were hatched in the presence of selenite and nano-Se ${ }^{b}$, respectively. In contrast, the hatching rates of embryos exposed to nano-Se ${ }^{\mathrm{cs}}$ were delayed compared with selenite and nano-Se ${ }^{b}$ even at the lowest concentration $(0.2 \mathrm{mg} / \mathrm{L})$ and only $75 \%$ were hatched at $72 \mathrm{hpf}$. With an increase in nano-Se ${ }^{\mathrm{cs}}$ concentration, the hatching rate decreased further 
(A)

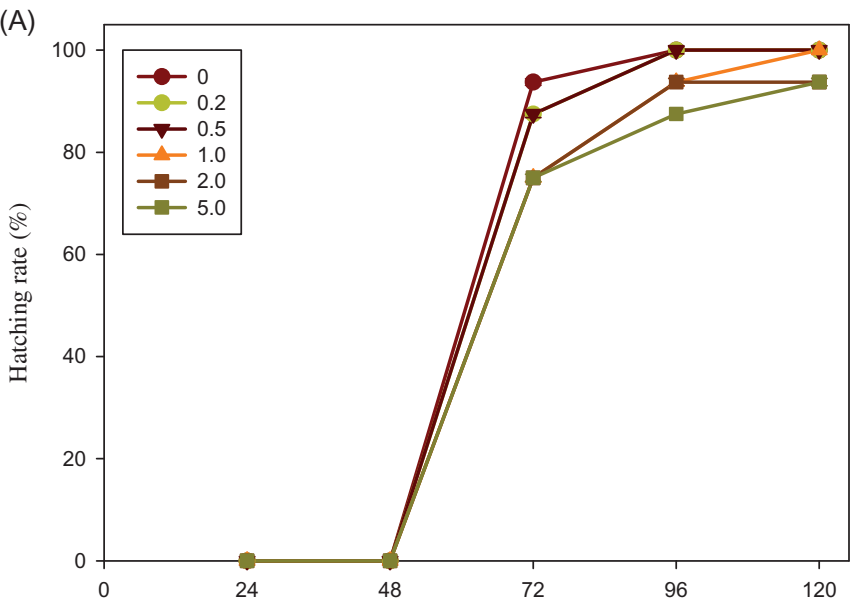

(C)

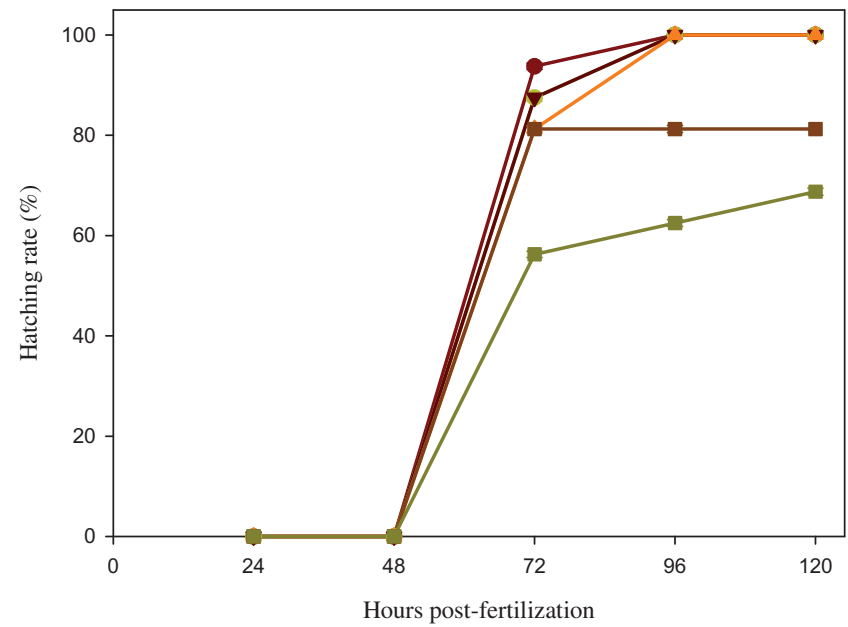

(B)

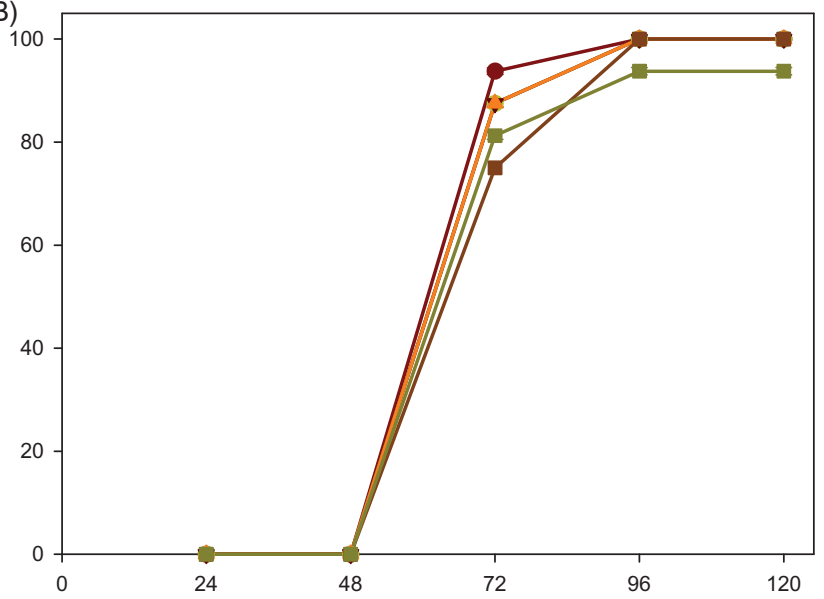

(D)

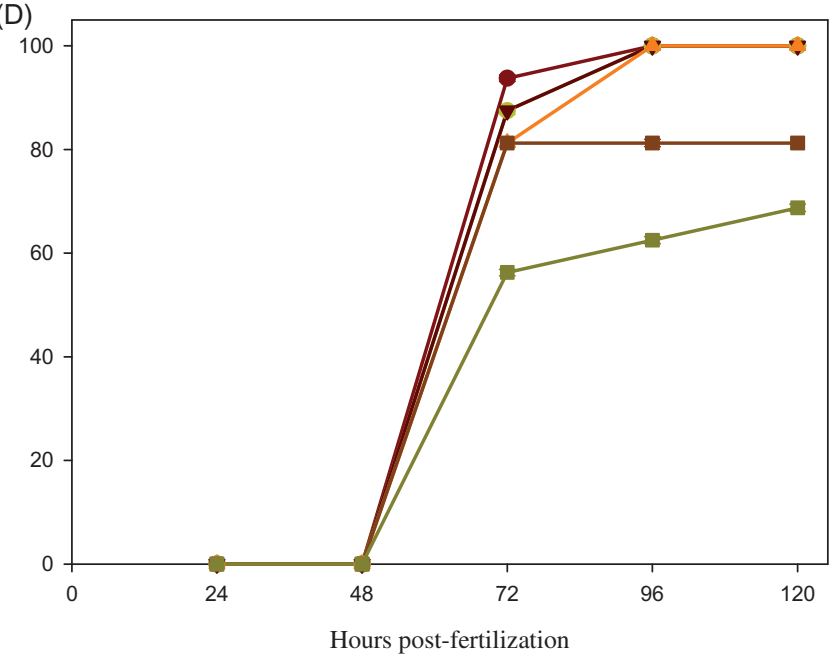

Figure 3. Time course of hatching rate of surviving zebrafish embryos exposed to (A) selenite, (B) nano-Se ${ }^{\mathrm{b}}$, (C) nano-Se ${ }^{\mathrm{cl}}$, and (D) nano-Se ${ }^{\mathrm{cs}}$ suspensions from $24 \mathrm{~h}$ to $120 \mathrm{~h}$ post-fertilization (hpf). Legend symbols are inside the panel (A).

and only $25 \%$ embryos were hatched at $5 \mathrm{mg} / \mathrm{L}$ at $72 \mathrm{hpf}$. The hatching rate in the presence of nano-Se ${ }^{c l}$ was not significantly affected as it did not show any substantial difference with the control at concentrations $<2 \mathrm{mg} / \mathrm{L}$ Se. However, at $5 \mathrm{mg} / \mathrm{L}$ concentration of nano-Se ${ }^{\mathrm{cl}}$, only $60 \%$ of embryos were hatched at 72 hpf.

From Figure 4, it was evident that at $48 \mathrm{hpf}$, neither selenite nor any of nano-Se showed mortality even at the highest concentration $(5 \mathrm{mg} / \mathrm{L})$ tested, but mortality was evident after that. Nano$\mathrm{Se}^{\mathrm{cs}}$ showed higher mortality at $72 \mathrm{hpf}$ than both nano-Se ${ }^{\mathrm{b}}$ and nano-Se ${ }^{\mathrm{cl}}$. Even at $1 \mathrm{mg} / \mathrm{L} \mathrm{Se}$, nano-Se ${ }^{\mathrm{cs}}$ caused $56.25 \%$ mortality at $72 \mathrm{hpf}$, while neither selenite nor nano-Se ${ }^{\mathrm{b}}$ showed mortality at this time point (Figure 4). The \% mortality of zebrafish embryos following exposure to selenite and different nano-Se at $120 \mathrm{hpf}$ are given in Figure 5. Exposure of embryos to different concentrations of selenite and different nano-Se suspensions caused a range of mortalities at $120 \mathrm{hpf}$. The $\mathrm{LC}_{50}$ values and $95 \%$ confidence interval $(\mathrm{Cl})$ of selenite and nano-Se ${ }^{\mathrm{b}}$ were $0.55(0.51-0.59)$ $\mathrm{mg} / \mathrm{L}$ and $1.77(1.59-1.98) \mathrm{mg} / \mathrm{L}$, respectively. It is evident that particle size did not have a significant effect on nano-Se ${ }^{c}$ toxicity as the $\mathrm{LC}_{50}$ values and $95 \% \mathrm{Cl}$ of nano-Se $\mathrm{Cs}^{\mathrm{cs}}$ and nano-Se $\mathrm{Cl}^{\mathrm{cl}}$ were comparable at $0.16(0.15-0.17) \mathrm{mg} / \mathrm{L}$ and $0.17(0.15-0.19) \mathrm{mg} / \mathrm{L}$ (Figure 5). It also implies that nano-Se ${ }^{\mathrm{b}}$ was 10 times less toxic than nano-Se ${ }^{c}$ independent of size. So, toxicity of the selenium compounds investigated on zebrafish embryos was observed in the following order: nano-Se ${ }^{b}<$ selenite $<$ nano-Se ${ }^{c s} \sim$ nano-Se ${ }^{c l}$.

\section{Discussion}

\section{Comparison of fate and toxicity of nano-Se ${ }^{b}$ with selenite and nano-Se}

One major drawback of microbial bioremediation of selenium oxyanions is that a fraction of nano-Se ${ }^{b}$ formed in bioreactors will remain suspended in the treated effluents leaving the bioreactors, thus nano-Se ${ }^{b}$ entering the aquatic environments (Lenz et al., 2008; Soda et al., 2011). Moreover, the selenium discharge criteria for aquatic life and the proposed toxicity thresholds are highly debated in recent times (Chapman, 1999; DeForest et al., 1999). In spite of concerns of Se toxicity to aquatic ecosystems, there are no studies on the toxic effect of biogenic nano-Se on aquatic organisms. Hence, the fate and the toxicity of nano-Se ${ }^{b}$ formed by anaerobic granular sludge biofilms were investigated on zebrafish embryos and compared with the fate and toxicity of selenite and chemogenic nano-Se.

Under normal assay conditions, zebrafish embryos hatch at approximately 72 hpf (Hua et al., 2014). Compared with the controls, the hatching rates associated with selenite and nano-Se ${ }^{b}$ exposure were not significantly delayed during the $96 \mathrm{~h}$ exposure time (Figure 3). However, increasing nano-Se $\mathrm{e}^{\mathrm{cs}}$ and nano-Se $\mathrm{Cl}^{\mathrm{cl}}$ concentrations had an inhibitory effect on the hatching rate and success (Figure 3). It is possible that the nano- $\mathrm{Se}^{c}$ suspension inhibited the secretion and activity of the hatching enzyme chorionase of zebrafish, as reported previously for other NPs like $\mathrm{Cu}$ 
(A)

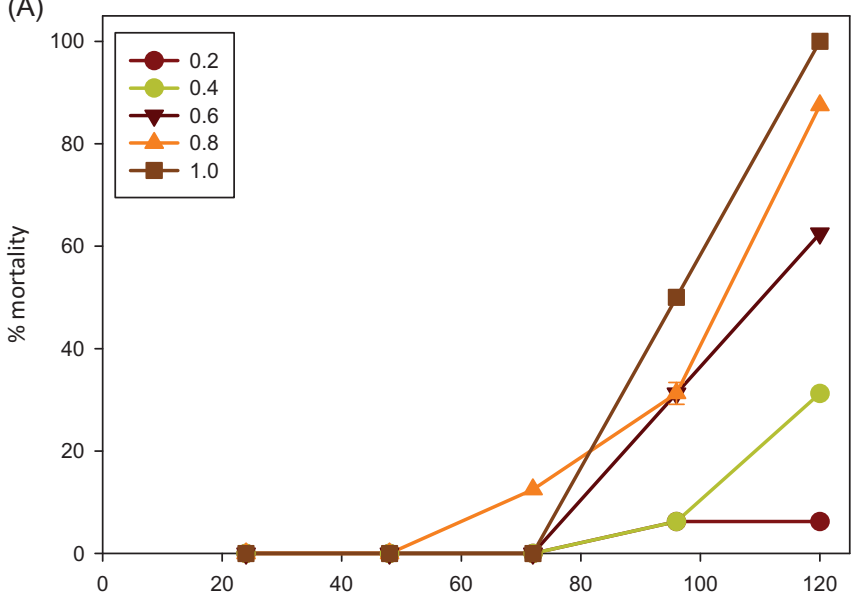

(C)

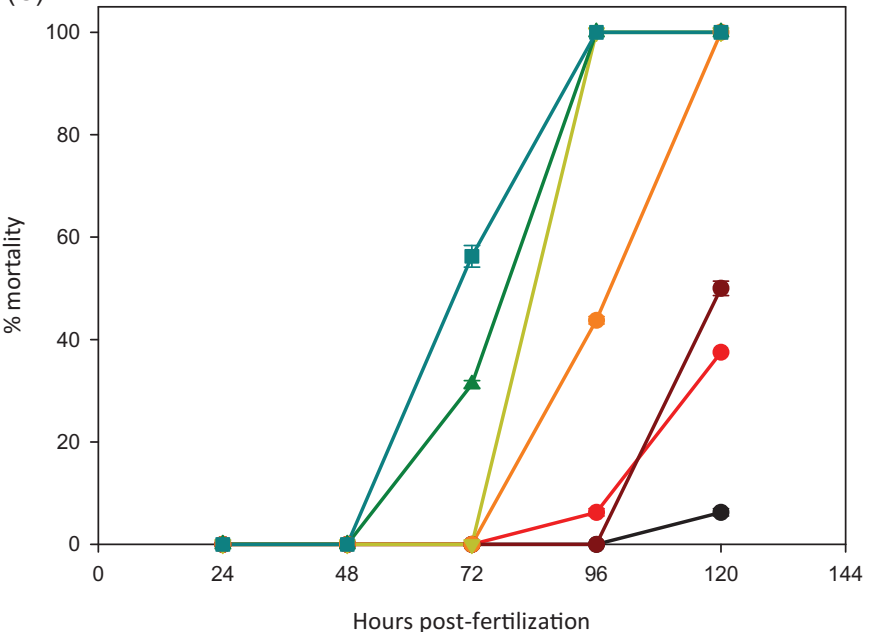

(B)

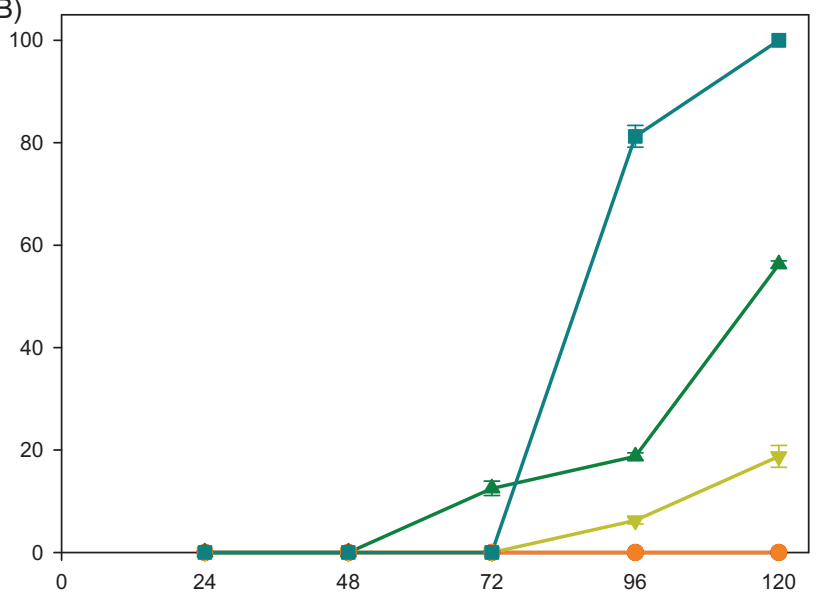

(D)

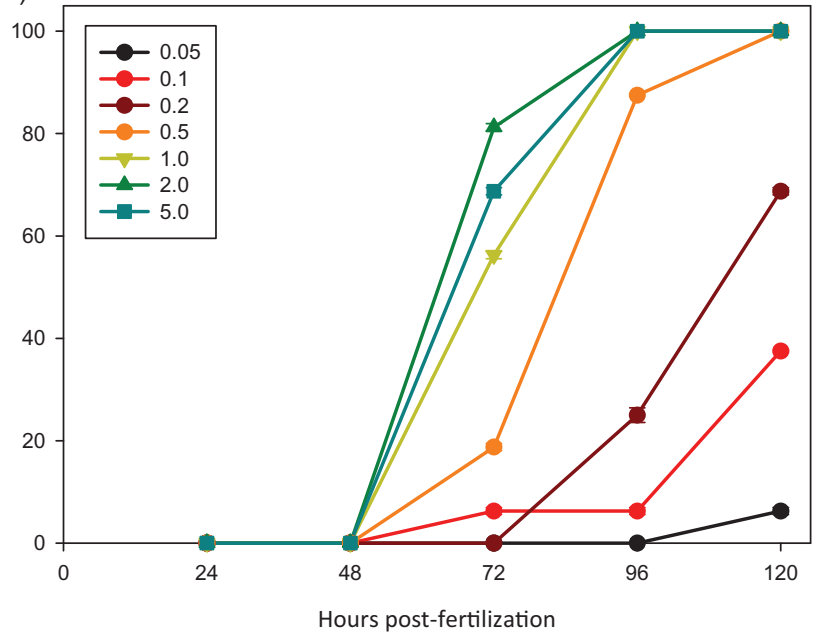

Figure 4. Time course of mortality of zebrafish embryos exposed to (A) selenite (legend symbols are inside), (B) nano-Se $\mathrm{b}^{\mathrm{b}}$, (C) nano-Se ${ }^{\mathrm{cl}}$, and (D) nano-Se ${ }^{\mathrm{cs}}$ suspensions from $24 \mathrm{~h}$ to $120 \mathrm{~h}$ post-fertilization (hpf). (B-D) Legend symbols are inside the panel (D).

and Zn NPs (Nel et al., 2006). Surprisingly, nano-Se ${ }^{\mathrm{cs}}$ and nano-Se ${ }^{\mathrm{cl}}$ had a different effect on hatching, but they induced comparable mortality on zebrafish embryos. Although the exact mechanisms of hatching inhibition are not known, it is possible that the mechanisms of action of lethality and of hatching inhibition by NPs on zebrafish embryos are different (Hua et al., 2014).

Based on the $\mathrm{LC}_{50}$ values (Figure 5), nano-Se ${ }^{\mathrm{b}}$ was 3.2 -fold less toxic than selenite and 10 -fold less toxic than nano-Se ${ }^{c}$. This result is in contrast to Zhang et al. (2001, 2005) and Wang et al. (2007), where it was reported that chemogenic nano-Se had 7-fold and 3.5-fold lower acute toxicity than sodium selenite and L-selenomethionine, respectively, in Kunming mice. However, Li et al. (2008) reported that chemogenic nano-Se particles were more toxic than selenite in medaka fish. Recently, Shakibaie et al. (2013) also reported that biogenic nano-Se synthesized by Bacillus sp. MSh-1 was less toxic than chemogenic nano-Se and $\mathrm{SeO}_{2}$ in mice. The discrepancy in the toxicities of nano-Se can result from the differences in nano-Se particle size, surface-stabilizing agents, medium composition, and test organisms.

The relative contribution to toxicity of nano-Se $\mathrm{e}_{\text {particle }}$ and $\mathrm{Se}_{\text {ion }}$ of all three nano-Se to zebrafish embryos using response addition and concentration addition was calculated (Equation (2)). The toxicity of the $\mathrm{Se}_{\text {ion }}$ shedded off from the nano-Se was determined by the concentration-response curve of selenite. Selenite at $100 \mu \mathrm{g} / \mathrm{L}$ showed no mortality on embryos, while selenate is reported to be much less toxic than selenite (Zannoni et al., 2008). Although details of speciation of nano-Se $\mathrm{e}_{\text {ion }}$ could not be determined, as the dissolution of nano-Se was marginal (maximum dissolution $84 \mu \mathrm{g} / \mathrm{L}$ for nano-Se $\mathrm{e}^{\mathrm{cl}}$ ) after $24 \mathrm{~h}$ incubation, toxicity caused by the released $\mathrm{Se}_{\text {ion }}$ was negligible. The nano-Se $\mathrm{e}_{\text {particle }}$ of all three types of nano-Se investigated was thus found to be the main factor causing toxicity to zebrafish embryos.

Interestingly, BSA capped nano-Se with two different sizes such as nano-Se $\mathrm{Cs}^{\mathrm{cs}}(25-90 \mathrm{~nm})$ and nano-Se ${ }^{\mathrm{cl}}(50-250 \mathrm{~nm})$ showed no significant $(p>0.05)$ difference in $\mathrm{LC}_{50}$ values (Figure 5$)$. The dissolution kinetics (Figure S3) of nano-Se $\mathrm{cs}^{\mathrm{cs}}$ and nano-Se $\mathrm{Cl}^{\mathrm{cl}}$ were also similar, suggesting that particle size has no effect on the fate and toxicity of nano-Se. Although there is a difference in size of nano$\mathrm{Se}^{\mathrm{b}}(185 \mathrm{~nm})$ and nano-Se $\mathrm{cl}^{\mathrm{cl}}(114 \mathrm{~nm})$, response-wise this size difference does not have a significant biological meaning based on Zhang et al. (2004). Moreover, it is not possible to synthesize larger BSA-capped nano-Se, as it formed an in-homogenous solution of nano-Se $e^{c}$ at sizes above $200 \mathrm{~nm}$. A similar finding regarding the formation of unstable and an in-homogenous selenium nanoparticles under comparable conditions was also reported by Zhang et al. (2004). The nano-Se ${ }^{c}$ (size $>200 \mathrm{~nm}$ ) starts precipitating after $1 \mathrm{~h}$ of incubation, while nano-Se ${ }^{\mathrm{b}}$ with a size range of $100-400 \mathrm{~nm}$ was stable and no precipitation was observed even after $24 \mathrm{~h}$ of incubation, clearly indicating the difference in nano$\mathrm{Se}^{\mathrm{b}}$ and nano-Se 

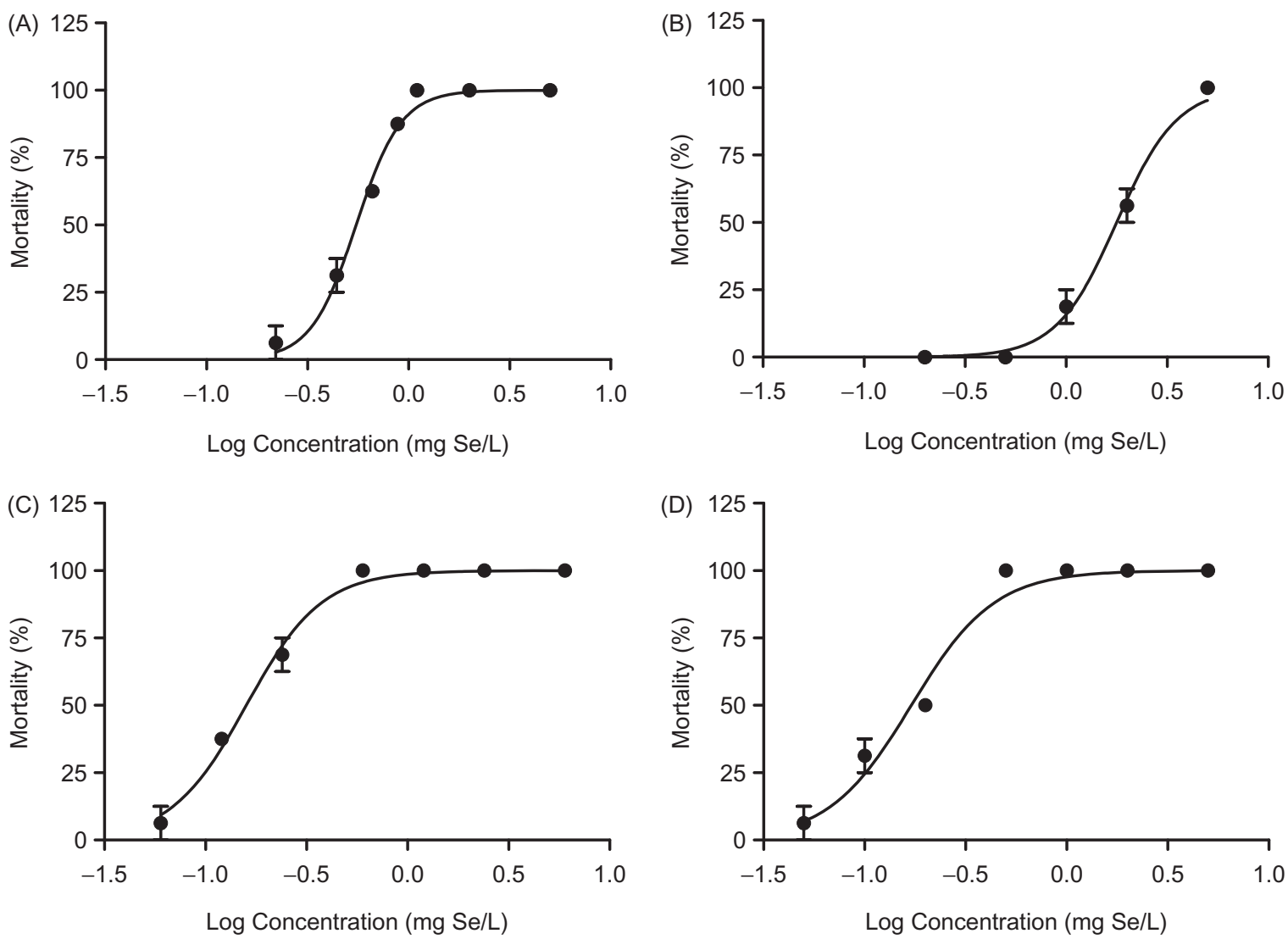

Figure 5. Dose-response curves of mortality of zebrafish embryos at $120 \mathrm{~h}$ postfertilization following exposure to (A) selenite, (B) nano-Se ${ }^{\mathrm{b}}$, (C) nano-Se ${ }^{\mathrm{cl}}$, and (D) nano-Se $e^{\text {cs. }}$

The physiochemical stability of biogenic Se nanospheres is already reported to be higher than that of chemically synthesized Se nanospheres (Oremland et al., 2004) and the presence of proteins in EPS possibly help in stabilizing nano-Se ${ }^{\mathrm{b}}$ (Sharma et al., 2014). Higher zeta-potential values (Table 1) and lower dissolution kinetics of nano-Se ${ }^{b}$ (Figure S3) compared with nano-Se ${ }^{c}$ support the contention that they both behave differently in terms of physicochemical stability and toxicity and the surface modification (capping agent) probably plays an important role in determining the fate of nano-Se (Gunsolus et al., 2015; Misra et al., 2012). Jain et al. (2015) also reported that in the absence of EPS originating from the same anaerobic granular sludge as used in the present study, unstable selenium "wire" was formed instead of selenium "nanosphere" under comparable experimental conditions. Liu and Hurt (2010) also showed that adsorption of NOM inhibited the ionic silver release from nano-Ag, while Moreau et al. (2007) reported that microbially-derived extracellular proteins changes the transport properties of biogenic ZnS nanoparticles by retarding their dispersal.

Recently, Fang et al. (2015) reported that aggregation and hydrodynamic diameter of $\mathrm{TiO}_{2}$ nanoparticles in suspensions are not the deciding factors for the toxicity of $\mathrm{TiO}_{2}$ nanoparticles on zebrafish (Danio rerio), rather it was the humic acid which decreases the bioavailability along with suppression of oxidative stress. However, studies on the effect of organic matter or EPS as surface coating on nano-Se are limited and more studies are required to link the surface coating of nano-Se with their properties, including their stability and dissolution in order to fully understand their environmental transformation, transport, and fate.

\section{Effect of EPS on nano-Se toxicity}

Nano-Se ${ }^{b}$ and nano-Se $e^{c}$ showed very contrasting toxic effects on zebrafish embryo development. The differences in toxicity can be attributed to the difference in surface stabilizing agents of nano$\mathrm{Se}^{\mathrm{b}}$ and nano-Se $\mathrm{e}^{\mathrm{c}}$. Nano-Se $\mathrm{e}^{\mathrm{c}}$ is stabilized by a single protein (BSA), while nano- $\mathrm{Se}^{\mathrm{b}}$ is stabilized by a complex mixture of biomolecules present on the surface of nano-Se ${ }^{b}$ possibly originating from the microorganisms present in the anaerobic granular sludge biofilms (Jain et al., 2015). The presence of characteristic peaks for proteins, SMPs, and fulvic and humic-like acids in nano-Se ${ }^{\mathrm{b}}$ provided evidence of the complex nature of the EPS in stabilizing nano-Se (Figure 2). A recent study showed that EPS extracted from anaerobic granular sludge directs the surface characteristics of chemogenic nano-Se similar to the biogenic nano-Se formed by anaerobic granular sludge (Jain et al., 2015).

Recently, Bondarenko et al. (2016) showed that the addition of a surface coating of levan, a fructose-composed biopolymer of bacterial origin, significantly reduced the toxic effects of Se-NPs in an in vitro assay on the human cell line Caco-2 cell line (colorectal adenocarcinomatous tissue of the human colon). Interestingly, the presence of recalcitrant components of EPS such as humic-like acids can reduce the bioavailability of contaminants to organisms due to the increased electrostatic repulsion (Lundqvist et al., 2010; Tang et al., 2015). A decrease in the selenium uptake by plant roots due to interactions between selenite and fulvic acids was reported (Wang et al., 1996), and it was suggested that association of selenium with organic matter in aquatic environments may play an important role in the mobility and bioavailability of selenium. 
There are clear indications that the presence of humic acid-like components in the surface coating by EPS limits the bioavailability of nanoparticles and attenuates their toxicity. Gao et al. (2012) showed that by increasing the humic acids concentration in a surface coating, the toxicity of silver nanoparticles to Daphina magna was decreased. Moreover, the presence of humic acids inhibits the generation of intracellular reactive oxygen species (ROS) and cellular lipid peroxidation which could be responsible for the lower toxicity of nanoparticles coated with natural organic matter (Lin et al., 2012; Yin et al., 2010). In contrast, BSA is commonly used to increase the bioavailability of NPs in in vivo or in vitro drug delivery (Kim et al., 2009). While BSA increases the colloidal stability of nanoparticles, it also increases the bioavailability of nano-Se ${ }^{c}$, thereby making the particles to be more toxic.

Furthermore, from Table 1, it is clear that the $\zeta$-potential is much higher in nano-Se ${ }^{b}(-28.5 \pm 5 \mathrm{mV})$ than nano-Se $\mathrm{Ss}^{\mathrm{cs}}$ $(-16 \pm 3.1 \mathrm{mV})$ and nano-Se $\mathrm{cl}^{\mathrm{ll}}(-13.7 \pm 3.6 \mathrm{mV})$. Thus, there is a higher degree of repulsion between the nano-Se ${ }^{b}$ and zebrafish embryos due to electrostatic repulsion. But due to the lower negative potential in nano-Se ${ }^{\mathrm{cs}}$ and nano- $\mathrm{Se}^{\mathrm{cl}}$, the electrostatic repulsion is reduced which possibly increases the chances of the interaction of nano-Se ${ }^{c}$ with embryos and results in higher toxicity (El Badawy et al., 2011). Recently, Gilbertson et al. (2015) reported that surface charge of multi-walled carbon nanotube has the greatest influence on the zebrafish mortality. Several other studies elucidated that the surface charge plays an important role in the observed toxicity trends of nanomaterials using either Daphnia magna or embryonic zebrafish as the in vivo model organisms, which is hypothesized to be governed primarily by the electrostatic interaction between the material and model organism (Bozich et al., 2014; Lee et al., 2013). Based on the data, it is contended that the presence of EPS increases the colloidal stability of nano-Se and prevents interaction of biogenic Se particles and embryos due to electrostatic repulsion (Buchs et al., 2013; Lin et al., 2012). This leads to lower bioavailability (uptake) and lower toxicity of nano-Se $\mathrm{S}^{\mathrm{b}}$ suggesting that EPS play a critical role in determining the fate and toxicity of biogenic Se nanoparticles.

\section{Environmental implications}

Although full-scale biological systems are available for treating selenium wastewaters, due to colloidal properties, a fraction of biogenic nano-Se will remain in the treated waters, thus leaving the bioreactors with the effluent (Lenz et al., 2008; Soda et al., 2011). The present study provided for the first time experimental evidence that nano-Se ${ }^{b}$ formed by the biofilms in the bioreactors is comparatively much less toxic to aquatic organisms than selenite and nano-Sec. This has implications in alleviating the concerns of nano-Se ${ }^{b}$ leaving the bioreactors and possibly adoption of new procedures and guidelines on selenium toxicity evaluation.

Moreover, Se is a semiconductor and scarce element (Nancharaiah et al., 2016) used in many applications like production of photovoltaic cells, rectifiers, and Se-coated cylindrical drums for xerography (Poborchii et al., 1998) and there has been an increased interest in synthesizing selenium nanoparticles using microorganisms as inexpensive "green" catalysts (Nancharaiah \& Lens, 2015b). While the rapid development in the synthesis and commercialization of nano-Se along with other nanomaterials is imminent, these trends may pose hazards to ecosystem well-being and human health. The present study suggests that more emphasis should be given to the use of biological synthesis for commercial production of nano-Se. The toxicity profiles of nano$\mathrm{Se}^{\mathrm{b}}$ and nano-Se ${ }^{c}$ also demonstrate the importance of selecting the surface coating materials while considering safer nano-Se for environmental purposes, or antimicrobial nano-Se for biomedical applications. This study highlights the need for additional studies on surface modified nano-Se, particularly on the biochemical identity and role of EPS components in biogenesis, fate, and toxicity of biogenic $\mathrm{Se}(0)$ nanoparticles under environmentally relevant conditions.

\section{Conclusions}

This study provided evidence that biogenic nano-Se is 3.2 -fold less toxic than selenite and 10 -fold less toxic than chemogenic nano-Se to zebrafish. In addition, smaller sized and larger sized BSA capped chemogenic nano-Se showed comparable LC $_{50}$ values on zebra fish embryos. $\mathrm{LC}_{50}$ values with $95 \% \mathrm{Cl}$ for selenite, nano$\mathrm{Se}^{\mathrm{b}}$, nano-Se ${ }^{\mathrm{cs}}$, and nano-Se ${ }^{\mathrm{cl}}$ were $0.55(0.51-0.59) \mathrm{mg} / \mathrm{L}, 1.77$ (1.59-1.98) mg/L, $0.16(0.15-0.17) \mathrm{mg} / \mathrm{L}$, and $0.17(0.15-0.19) \mathrm{mg} /$ $L$, respectively. Biogenic nano-Se was found to be more stable in terms of dissolution kinetics compared with chemogenic nano-Se. 3D-EEM analysis of organic matter associated with biogenic nanoSe showed distinct peaks for proteins, soluble microbial products, and humic acids typical for EPS matrix of biofilms.

\section{Acknowledgements}

The authors would like to thank Gerda Lamers (Leiden University) for the technical help of transmission electron microscopy.

\section{Disclosure statement}

The authors declare that there are no conflicts of interest.

\section{Funding}

This research was supported through the Erasmus Mundus Joint Doctorate Environmental Technologies for Contaminated Solids, Soils, and Sediments (ETeCoS 3 , FPA no. 2010-0009) and the Marie Curie International Incoming Fellowship Role of biofilm-matrix components in the extracellular reduction and recovery of chalcogens (BioMatch, project No. 103922).

\section{References}

Backhaus T, Scholze M, Grimme LH. 2000. The single substance and mixture toxicity of quinolones to the bioluminescent bacterium Vibrio fischeri. Aquat Toxicol 49:49-61.

Baker A, Lamont-Black J. 2001. Fluorescence of dissolved organic matter as a natural tracer of ground water. Ground Water 39:745-50.

Bhatia D, Bourven I, Simon S, Bordasa F, van Hullebusch ED, Rossano S, et al. 2013. Fluorescence detection to determine proteins and humic-like substances fingerprints of exopolymeric substances (EPS) from biological sludges performed by size exclusion chromatography (SEC). Bioresour Technol 131:159-65.

Bondarenko OM, Ivask A, Kahru A, Vija H, Titma T, Visnapuu M, et al. 2016. Bacterial polysaccharide levan as stabilizing, nontoxic and functional coating material for microelement-nanoparticles. Carbohyd Polym 20:710-20.

Bozich JS, Lohse SE, Torelli MD, Murphy CJ, Hamers RJ, Klaper RD. 2014. Surface chemistry, charge and ligand type impact the toxicity of gold nanoparticles to Daphnia magna. Environ Sci Nano 1:260-70.

Buchs B, Evangelou MW, Winkel LH, Lenz M. 2013. Colloidal properties of nanoparticular biogenic selenium govern 
environmental fate and bioremediation effectiveness. Environ Sci Technol 47:2401-7.

Chapman PM. 1999. Selenium-a potential time bomb or just another contaminant? Hum Ecol Risk Assess 5:1123-38.

DeForest DK, Brix KV, Adams WJ. 1999. Critical review of proposed residuebased selenium toxicity thresholds for freshwater fish. Hum Ecol Risk Assess 5:1187-228.

Dennis LA. 2004. Aquatic selenium pollution is a global environmental safety issue. Ecotoxicol Environ Saf 59:44-56.

El Badawy AM, Silva RG, Morris B, Scheckel KG, Suidan MT, Tolaymat TM. 2011. Surface charge-dependent toxicity of silver nanoparticles. Environ Sci Technol 45:283-7.

Fang T, Yu LP, Zhang WC, Bao SP. 2015. Effects of humic acid and ionic strength on $\mathrm{TiO}_{2}$ nanoparticles sublethal toxicity to zebrafish. Ecotoxicology 24:2054-66.

Gao J, Powers K, Wang Y, Zhou H, Roberts SM, Moudgil BM, et al. 2012. Influence of Suwannee River humic acid on particle properties and toxicity of silver nanoparticles. Chemosphere 89:96-101.

Gilbertson LM, Melnikov F, Wehmas LC, Anastas PT, Tanguay RL, Zimmerman JB. 2015. Toward safer multi-walled carbon nanotube design: establishing a statistical model that relates surface charge and embryonic zebrafish mortality. Nanotoxicology 10:10-19.

Gunsolus IL, Mousavi MP, Hussein K, Bühlmann P, Haynes CL. 2015. Effects of humic and fulvic acids on silver nanoparticle stability, dissolution, and toxicity. Environ Sci Technol 49:8078-86.

Hua J, Vijver MG, Ahmad F, Richardson MK, Peijnenburg WJ. 2014. Toxicity of different-sized copper nano- and submicron particles and their shed copper ions to zebrafish embryos. Environ Toxicol Chem 33:1774-82.

Jain R, Jordan N, Schild D, van Hullebusch ED, Weiss S, Franzen C, et al. 2015. Extracellular polymeric substances govern the surface charge of biogenic elemental selenium nanoparticles. Environ Sci Technol 49:1713-20.

Kim BS, Oh JM, Kim KS, Seo KS, Cho JS, Khang G, et al. 2009. BSAFITC-loaded microcapsules for in vivo delivery. Biomaterials 30:902-9.

Lee KJ, Browning LM, Nallathamby PD, Xu XH. 2013. Study of charge-dependent transport and toxicity of peptide-functionalized silver nanoparticles using zebrafish embryos and single nanoparticle plasmonic spectroscopy. Chem Res Toxicol 26:904-17.

Leenheer JA, Croue JP. 2003. Characterizing aquatic dissolved organic matter. Environ Sci Technol 37:18-26.

Lenz M, Lens PNL. 2009. The essential toxin: the changing perception of selenium in environmental sciences. Sci Total Environ 407:3620-33.

Lenz $M$, van Hullebusch ED, Hommes G, Corvini PFX, Lens PNL. 2008. Selenate removal in methanogenic and sulfate-reducing upflow anaerobic sludge bed reactors. Water Res 42:2184-92.

Li HC, Zhang JS, Wang T, Luo WR, Zhou QF, Jiang GB. 2008. Elemental selenium particles at nanosize (Nano-Se) are more toxic to medaka (Oryzias latipes) as a consequence of hyperaccumulation of selenium: a comparison with sodium selenite. Aquat Toxicol 89:251-6.

Lin D, Ji J, Long Z, Yang K, Wu F. 2012. The influence of dissolved and surface-bound humic acid on the toxicity of $\mathrm{TiO}_{2}$ nanoparticles to Chlorella sp. Water Res 46:4477-87.

Liu H, Fang HH. 2002. Extraction of extracellular polymeric substances (EPS) of sludges. J Biotechnol 95:249-56.

Liu JY, Hurt RH. 2010. Ion release kinetics and particle persistence in aqueous nano-silver colloids. Environ Sci Technol 44:2169-75.
Lohr JL, Yost HJ. 2000. Vertebrate model system in the study of early heart development: xenopus and zebrafish. Am J Med Genet 97:248-257.

Lundqvist A, Bertilsson S, Goedkoop W. 2010. Effects of extracellular polymeric and humic substances on chlorpyrifos bioavailability to Chironomus riparius. Ecotoxicology 19:614-22.

Luoma SN, Johns C, Fisher NS, Steinberg NA, Oremland RS, Reinfelder JR. 2000. Determination of selenium bioavailability to a benthic bivalve from particulate and solute pathways. Environ Sci Technol 26:485-91.

Maeng SK, Sharma SK, Abel CD, Magic-Knezev A, Song KG, Amy GL. 2012. Effects of effluent organic matter characteristics on the removal of bulk organic matter and selected pharmaceutically active compounds during managed aquifer recharge: column study. J Contam Hydrol 140-141:139-49.

Mal J, Nancharaiah YV, van Hullebusch ED, Lens PNL. 2016. Effect of heavy metal co-contaminants on selenite bioreduction by anaerobic granular sludge. Bioresour Technol 206:1-8.

Misra SK, Dybowska A, Berhanu D, Luoma SN, Valsami-Jones E. 2012. The complexity of nanoparticle dissolution and its importance in nanotoxicological studies. Sci Total Environ 438:225-32.

Moreau JW, Weber PK, Martin MC, Gilbert B, Hutcheon ID, Banfield JF. 2007. Extracellular proteins limit the dispersal of biogenic nanoparticles. Science 316:1600-3.

Nancharaiah YV, Lens PNL. 2015a. Ecology and biotechnology of selenium-respiring bacteria. Microbiol Mol Biol Rev 79:61-80.

Nancharaiah YV, Lens PNL. 2015b. Selenium biomineralization for biotechnological applications. Trends Biotechnol 33:323-30.

Nancharaiah YV, Venkata Mohan S, Lens PNL. 2016. Biological and bioelectrochemical recovery of critical and scarce metals. Trends Biotechnol 34:137-55.

Nel A, Xia T, Madler L, Li N. 2006. Toxic potential of materials at the nanolevel. Science 311:622-7.

Oremland RS, Herbel MJ, Blum JS, Langley S, Beveridge TJ, Ajayan PM, Sutto T. 2004. Structural and spectral features of selenium nanospheres produced by Se-respiring bacteria. Appl Environ Microbiol 70:52-60.

Organisation for Economic Co-operation and Development. 2011. Validation report (phase 1) for the zebrafish embryo toxicity test, part I. Series on Testing and Assessment no. 157. ENV/JM/ MONO (2011) 37 Paris, France.

Pearce Cl, Pattrick RAD, Law N, Charnock JM, Coker VS, Fellowes WJ, et al. 2009. Investigating different mechanisms for biogenic selenite transformations: Geobacter sulfurreducens, Shewanella oneidensis and Veillonella atypica. Environ Technol 30:1313-26.

Poborchii VV, Kolobov AV, Tanaka K. 1998. An in-situ Raman study of polarization-dependent photocrystallization in amorphous selenium films. Appl Phys Lett 72:1167-9.

Ray D, Paul BK, Guchhait N. 2012. Effect of biological confinement on the photophysics and dynamics of a proton-transfer phototautomer: an exploration of excitation and emission wavelength-dependent photophysics of the protein-bound drug. Phys Chem Chem Phys 14:12182-92.

Rayman MP. 2006. The importance of selenium to human health. Lancet 356:23-241.

Scheinost AC, Kirsch R, Banerjee D, Fernandez-Martinez A, Zaenker H, Funke H, Charlet L. 2008. X-ray absorption and photoelectron spectroscopy investigation of selenite reduction by Fell-bearing minerals. J Contam Hydrol 102:228-45.

Schlekat CE, Dowdle PR, Lee BG, Luoma SN, Oremland RS. 2000. Bioavailability of particle-associated $\mathrm{Se}$ to the bivalve Potamocorbula amurensis. Environ Sci Technol 30:4504-10.

Shakibaie M, Shahverdi AR, Faramarzi MA, Hassanzadeh GR, Rahimi HR, Sabzevari O. 2013. Acute and subacute toxicity of 
novel biogenic selenium nanoparticles in mice. Pharm Biol 51:58-63.

Sharma VK, Siskova KM, Zboril R, Gardea-Torresdey JL. 2014. Organic-coated silver nanoparticles in biological and environmental conditions: fate, stability and toxicity. Adv Colloid Interface Sci 204:15-34.

Soda S, Kashiwa M, Kagami T, Kuroda M, Yamashita M, Ike M. 2011. Laboratory-scale bioreactors for soluble selenium removal from selenium refinery wastewater using anaerobic sludge. Desalination 279:433-438.

Srivastava N, Mukhopadhyay M. 2013. Biosynthesis and structural characterization of selenium nanoparticles mediated by Zooglea ramigera. Powder Technol 244:26-9.

Tang Y, Li S, Lu Y, Li Q, Yu S. 2015. The influence of humic acid on the toxicity of nano-ZnO and $\mathrm{Zn}^{2+}$ to the Anabaena sp. Environ Toxicol 30:895-903.

Wang H, Zhang J, Yu H. 2007. Elemental selenium at nano size possesses lower toxicity without compromising the fundamental effect on selenoenzymes: comparison with selenomethionine in mice. Free Radic Biol Med 42:1524-33.

Wang ZJ, Xu Y, Peng A. 1996. Influences of fulvic acid on bioavailability and toxicity of selenite for wheat seedling and growth. Biol Trace Elem Res 55:147-62.

Winkel LH, Johnson CA, Lenz M, Grundl T, Leupin OX, Amini M, Charlet L. 2012. Environmental selenium research: from microscopic processes to global understanding. Environ Sci Technol 46:571-9.

Yin H, Casey PS, McCall MJ, Fenech M. 2010. Effects of surface chemistry on cytotoxicity, genotoxicity, and the generation of reactive oxygen species induced by $\mathrm{ZnO}$ nanoparticles. Langmuir 26:15399-408.

Zannoni D, Borsetti F, Harrison JJ, Turner R. 2008. The bacterial response to the chalcogen metalloids Se and Te. Adv Microb Physiol 53:1-12.

Zhang J, Wang H, Bao Y, Zhang L. 2004. Nano red elemental selenium has no size effect in the induction of seleno-enzymes in both cultured cells and mice. Life Sci 75:237-44.

Zhang JS, Gao XY, Zhang LD, Bao YP. 2001. Biological effects of a nano red elemental selenium. Biofactors 15:27-38.

Zhang JS, Wang HL, Yan XX, Zhang LD. 2005. Comparison of short-term toxicity between Nano-Se and selenite in mice. Life Sci 76:1099-109.

Zhang W, Chen Z, Liu H, Zhang L, Gao P, Li D. 2011. Biosynthesis and structural characteristics of selenium nanoparticles by Pseudomonas alcaliphila. Colloid Surface B 88:196-201.

Zhang YQ, Moore JN. 1996. Selenium fractionation and speciation in a wetland system. Environ Sci Technol 30:2613-19.

Zhou M, Liu B, Lv C, Chen Z, Shen J. 2014. Rapid synthesis of NADPH responsive $C d S e$ quantum dots from selenium nanoparticles. RSC Adv 4:61133-6. 